\title{
Protection by Disulfiram and Diethyldithiocarbamate against Hypoxia-Induced Lethality in Mice
}

Tohru Masukawa and Kunio Nakanishi

Department of Clinical Biochemistry, Faculty of Pharmaceutical Sciences, Setsunan University, Nagaotoge-cho, Hirakata, Osaka 573-0I, Japan

Received May 21, 1993 Accepted July 21, 1993

\begin{abstract}
The effects of disulfiram (DS) and its major metabolite, diethyldithiocarbamate (DEDC), on the survival time under normobaric and hypobaric hypoxia were examined in mice. At an ambient temperature of $24^{\circ} \mathrm{C}$, DS at $0.5-3.0 \mathrm{mmol} / \mathrm{kg}$ (i.p.) caused a marked dose-dependent prolongation of the survival time in mice subjected to both types of hypoxia. DEDC also prolonged the survival time, but the effect was less at its higher doses which decreased brain superoxide dismutase. The maximum effects of DS and DEDC were found at $3 \mathrm{hr}$ and $1 \mathrm{hr}$ after injection, respectively. Of the metabolites of DEDC, the copper complex with DEDC caused a significant effect, whereas neither diethylamine nor carbon disulfide did. Furthermore, DS, DEDC and copper complex caused marked hypothermia, and the time course changes of hypothermia by DS and DEDC closely paralleled those of the degree of anti-hypoxic effects, respectively. At an ambient temperature of $36^{\circ} \mathrm{C}$, in which the body temperature was maintained near the normal level, both DS and DEDC still exhibited a weak anti-hypoxic effect. These results suggest that DEDC itself, formed as a metabolite of DS, and partly the copper complex produced the anti-hypoxic effect, which could not be explained by concomitant hypothermia alone.
\end{abstract}

Keywords: Disulfiram, Diethyldithiocarbamate, Hypoxia-induced lethality, Ambient temperature, Superoxide dismutase (brain)

The disulfide disulfiram (DS) is rapidly converted in vivo into two molecules of diethyldithiocarbamate (DEDC), its corresponding thiol, which is subsequently further biotransformed $(1-4)$. The former compound is in current usage in alcohol aversion therapy, and the latter compound is a potent chelator of copper and can inhibit various copper-containing enzymes such as superoxide dismutase (SOD) both in vitro and in vivo (5). DEDC is well known to exhibit a protective effect against liver injury induced by various hepatotoxins, and its effect was assumed to be based on inhibition of the mixed-function oxidase system, which activated the hepatotoxins to toxic metabolites (6-8). Furthermore, there were many reports dealing with the influence of DS and DEDC on oxygen toxicity in lungs and brain, although the results were different among investigators (9-13). However, there has been no information on the effects of DEDC and DS on hypoxic injury.

In the present study, we investigated the influences of DEDC and DS on cerebral hypoxic injury using a hypoxic mouse model, in which the survival time was measured in mice exposed to hypoxia.

\section{MATERIALS AND METHODS}

\section{Chemicals and animals}

DS, DEDC, diethylamine and carbon disulfide were obtained from Wako Pure Chemical Industries, Osaka. $(\mathrm{DEDC})_{2} \mathrm{Cu},(\mathrm{DEDC})_{2} \mathrm{Zn}$ and $(\mathrm{DEDC})_{3} \mathrm{Fe}$ were from Tokyo Kasei Kogyo Co., Ltd., Tokyo. Other reagents used were of analytical grade. The animals used were male ICR mice weighing about $30 \mathrm{~g}$ (5- to 6-week-old) and were obtained from Japan SLC, Inc., Hamamatsu. They were housed on a 12-hr light-dark cycle (light 7:00-19:00 hr) with food and water freely available. The experiments were usually carried out at a constant temperature of $24^{\circ} \mathrm{C}$. In the experiments evaluating the influence of an ambient temperature, at $90 \mathrm{~min}$ before the experiments, mice we introduced into a thermocontrolled room in which the ambient temperature was $36^{\circ} \mathrm{C}$.

\section{Experimental hypoxia}

In the test of normobaric hypoxia, mice were placed in a chamber (plastic desiccator, 2.5 l) through which a gas mixture of nitrogen and oxygen $(96: 4 \mathrm{v} / \mathrm{v})$ flowed at the 
rate of $51 / \mathrm{min}$. The survival time was determined by the time interval between the start of introduction of mice into the hypoxic gas chamber and the cessation of respiration.

In the test of hypobaric hypoxia, mice were placed in a chamber (glass desiccator, $12 \mathrm{l}$ ), equipped with a vacuum pump and manometer. The inside pressure of the chamber was lowered to $200 \mathrm{mmHg}$ within $25 \mathrm{sec}$ by initiating air suction. The survival time was determined by the time interval between the start of air suction and the cessation of respiration.

\section{Assay of body temperature}

Body temperature was measured with a thermister probe (SK-1250MC; Sato Keiryoki MFG. Co., Ltd., Tokyo), the tip of which was inserted to a depth of $2 \mathrm{~cm}$ into the anus of a mouse.

\section{Assay of SOD}

SOD was measured by the method of Heikkila and Cabbat which is based on the inhibitory action of SOD on the rate of 6-hydroxydopamine auto-oxidation (14).

\section{Statistical analysis}

Data were shown as the mean \pm S.E.M. Comparisons of the mean values were made by analysis of variance followed by Duncan's multiple range test.

\section{RESULTS}

At an ambient temperature of $24^{\circ} \mathrm{C}$, the survival time of the control mice averaged about 5 min under the normobaric hypoxic condition. Pretreatment for $0.5 \mathrm{hr}$ with DS $(1.00-3.00 \mathrm{mmol} / \mathrm{kg}$, i.p.) markedly and dose-dependently prolonged the survival time (Table 1). DEDC $(0.25-2.00 \mathrm{mmol} / \mathrm{kg})$ also caused a similar effect, but the effects were diminished in the case of higher doses, and they were completely abolished at a dose of $6.00 \mathrm{mmol} / \mathrm{kg}$.

In hypobaric hypoxia, the survival time of the control mice averaged about $3 \mathrm{~min}$. Under this condition, similar prolongation of the survival time was observed.

Figure 1 shows the time course of change of the antihypoxic effects induced by DEDC and DS. The maximum effect of DEDC was found at $1 \mathrm{hr}$ and disappeared at 3 $\mathrm{hr}$. The effect of DS lasted $3 \mathrm{hr}$, and its peak was found at $3 \mathrm{hr}$. DS was reported to be rapidly metabolized to DEDC (1-3). DEDC was known to be metabolized reductively into diethylamine and carbon disulfide $(1-3)$. Furthermore, there was an another metabolic pathway in which DEDC reacted with metal ions to form a chelate complex with metals, mainly the copper complex (4). Thus, the effects of these metabolites were examined (Table 2). While neither diethylamine nor carbon disulfide had any
Table 1. Effects of DS and DEDC on the survival time of mice exposed to either normobaric or hypobaric hypoxia at the ambient temperature of $24^{\circ} \mathrm{C}$

\begin{tabular}{|c|c|c|c|}
\hline \multirow{2}{*}{ Treatment } & \multirow{2}{*}{$\mathrm{mmol} / \mathrm{kg}$} & \multicolumn{2}{|c|}{ Survival time (min) } \\
\hline & & normobaric & hypobaric \\
\hline \multicolumn{4}{|l|}{ Exp. 1} \\
\hline \multicolumn{2}{|c|}{ Control (1.0\% CMC Na) } & $4.76 \pm 0.22$ & $3.29 \pm 0.29$ \\
\hline \multirow[t]{5}{*}{ DS } & 0.25 & $6.00 \pm 0.51$ & $3.41 \pm 0.26$ \\
\hline & 0.50 & $6.48 \pm 0.69$ & $4.84 \pm 0.45^{*}$ \\
\hline & 1.00 & $9.52 \pm 1.42^{* *}$ & $4.88 \pm 0.40^{*}$ \\
\hline & 2.00 & $9.66 \pm 0.77^{* *}$ & - \\
\hline & 3.00 & $11.77 \pm 1.26^{* *}$ & - \\
\hline \multirow[t]{4}{*}{ DEDC } & 0.25 & - & $4.46 \pm 0.49$ \\
\hline & 0.50 & - & $5.02 \pm 0.87$ \\
\hline & 1.00 & - & $6.44 \pm 0.69^{* *}$ \\
\hline & 2.00 & - & $10.04 \pm 1.13^{* *}$ \\
\hline \multicolumn{4}{|l|}{ Exp. 2} \\
\hline \multicolumn{2}{|c|}{ Control $(1.0 \%$ CMC Na) } & $4.31 \pm 0.22$ & - \\
\hline \multirow[t]{6}{*}{ DEDC } & 0.25 & $5.65 \pm 0.30^{* *}$ & - \\
\hline & 0.50 & $5.60 \pm 0.25^{*}$ & - \\
\hline & 1.00 & $6.87 \pm 0.55^{* *}$ & - \\
\hline & 2.00 & $7.50 \pm 0.52^{* *}$ & - \\
\hline & 4.00 & $6.48 \pm 0.67^{*}$ & - \\
\hline & 6.00 & $4.62 \pm 0.62$ & - \\
\hline
\end{tabular}

Mice were exposed to either normobaric or hypobaric hypoxia 30 min after intraperitoneal injection of the drug. Values represent the mean \pm S.E.M. of the results from 10 mice. Significantly different from the control $\left({ }^{*} \mathrm{P}<0.05,{ }^{* *} \mathrm{P}<0.01\right)$.

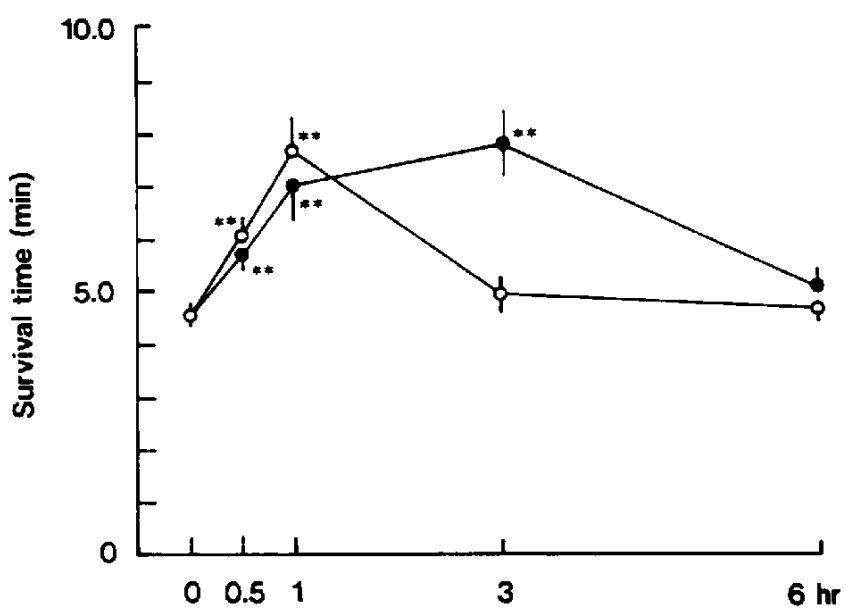

Fig. 1. Time course of the change of the anti-hypoxic effect induced by DEDC and DS in mice exposed to normobaric hypoxia. DEDC, $2.00 \mathrm{mmol} / \mathrm{kg}$, i.p. (O); DS, $1.00 \mathrm{mmol} / \mathrm{kg}$, i.p. (O). Points and bars represent the mean \pm S.E.M. of the results from 10 mice. Significantly different from the control $\left({ }^{* *} \mathrm{P}<0.01\right)$.

anti-hypoxic effect, the copper complex had a marked effect. The zinc complex exhibited a similar complex, but 
Table 2. Effects of various metabolites of DEDC on the survival time of mice exposed to normobaric hypoxia at the ambient temperature of $24^{\circ} \mathrm{C}$

\begin{tabular}{lll}
\hline Treatment & mmol/kg & Survival time (min) \\
\hline Exp. 1 & & \\
$\quad$ Control (sesame oil) & & $4.32 \pm 0.14$ \\
CS $_{2}$ & 0.5 & $4.54 \pm 0.19$ \\
& 1.0 & $4.31 \pm 0.16$ \\
Exp. 2 & & \\
Control (saline) & & $4.52 \pm 0.22$ \\
Diethylamine $\mathrm{HCl}$ & 0.5 & $4.54 \pm 0.29$ \\
& 1.0 & $4.66 \pm 0.24$ \\
Exp. 3 & & \\
Control (1.0\% CMC Na) & & $4.76 \pm 0.30$ \\
(DEDC) ${ }_{2} \mathrm{Cu}$ & 0.25 & $6.55 \pm 0.48^{*}$ \\
& 0.50 & $7.12 \pm 0.82^{* *}$ \\
(DEDC) ${ }_{3} \mathrm{Fe}$ & 1.00 & $7.63 \pm 0.84^{* *}$ \\
Exp. 4 & 1.00 & $5.17 \pm 0.36$ \\
Control (1.0\% CMC Na) & & \\
(DEDC) ${ }_{2} \mathrm{Zn}$ & 0.125 & $7.77 \pm 0.64^{* *}$ \\
& 0.25 & $7.85 \pm 0.58^{* *}$ \\
& 0.50 & $8.08 \pm 0.83^{* *}$ \\
& 1.00 & $8.79 \pm 0.82^{* *}$ \\
\hline
\end{tabular}

Mice were exposed to normobaric hypoxia $30 \mathrm{~min}$ after intraperitoneal injection of the drug. Values represent the mean \pm S.E.M. of the results from 10 mice. Significantly different from the control $\left({ }^{*} \mathrm{P}<0.05,{ }^{* *} \mathrm{P}<0.01\right)$.

the iron complex had no effect. From the above data, the effect of DS is likely to be developed via metabolic conversion into DEDC and also partly involves the DEDC-copper complex, although the anti-hypoxic effect of DS itself could not be excluded.

There have been many reports that the protection from the lethal effects of hypoxia by drugs can be accounted for by drug-induced hypothermia (15-17). Therefore, we examined the effect of the drug on body temperature, which was done by sequential measurement in the same mice over 5 or $6 \mathrm{hr}$. Both DS and DEDC markedly decreased body temperature (Fig. 2, A and B). The degree and duration of the hypothermia by DEDC were both dose-dependent, and the hypothermic effect was transient. The peak fall in body temperature occurred $0.5-1 \mathrm{hr}$ after injection. The degree of the hypothermic effect by DS was smaller during the earlier period, but the duration was longer: the peak fall was at 2-3 hr. The complexes of DEDC with copper and zinc caused dose-dependent hypothermia, and the effects were strengthened with the passing of time (Fig. 2, C and D). The complex with iron had no effect.

To elucidate the role of hypothermia in the anti-hypox-
Table 3. Effects of DEDC and DS on the survival time of mice exposed to either normobaric or hypobaric hypoxia at the ambient temperature of $36^{\circ} \mathrm{C}$

\begin{tabular}{|c|c|c|c|}
\hline \multirow{2}{*}{ Treatment } & \multirow{2}{*}{$\mathrm{mmol} / \mathrm{kg}$} & \multicolumn{2}{|c|}{ Survival time (min) } \\
\hline & & normobaric & hypobaric \\
\hline Control $(1.0 \%$ & CMC Na) & $3.94 \pm 0.12$ & $2.43 \pm 0.25$ \\
\hline \multirow[t]{3}{*}{ DEDC } & 0.5 & $4.38 \pm 0.21$ & $2.96 \pm 0.17$ \\
\hline & 1.0 & $4.52 \pm 0.17^{*}$ & $3.39 \pm 0.36^{*}$ \\
\hline & 2.0 & $4.65 \pm 0.23^{*}$ & $2.18 \pm 0.33$ \\
\hline \multirow[t]{3}{*}{ DS } & 0.5 & $3.54 \pm 0.11$ & $2.89 \pm 0.29$ \\
\hline & 1.0 & $4.73 \pm 0.30^{*}$ & $3.63 \pm 0.23^{* *}$ \\
\hline & 2.0 & $4.91 \pm 0.20^{* *}$ & $3.30 \pm 0.20^{*}$ \\
\hline
\end{tabular}

Mice were exposed to either normobaric or hypobaric hypoxia 30 min after intraperitoneal injection of the drug. Values represent the mean \pm S.E.M. of the results from 10 mice. Significantly different from the control ( $\left.{ }^{*} \mathrm{P}<0.05,{ }^{* *} \mathrm{P}<0.01\right)$.

Table 4. Effects of DEDC and DS on brain SOD content in mice

\begin{tabular}{|c|c|c|c|}
\hline Treatment & $\mathrm{mmol} / \mathrm{kg}$ & SOD ( $\mu \mathrm{g} / \mathrm{g}$ tissue) & $\%$ Inhibition \\
\hline \multicolumn{4}{|l|}{ Exp. 1} \\
\hline \multicolumn{2}{|c|}{ Control (1.0\% CMC Na) } & $118.1 \pm 6.0(8)$ & - \\
\hline \multirow[t]{2}{*}{ DEDC } & 0.5 & $114.3 \pm 5.2(8)$ & 3.2 \\
\hline & 1.0 & $115.8 \pm 5.7(8)$ & 1.9 \\
\hline \multirow[t]{2}{*}{ DS } & 0.5 & $119.6 \pm 7.4(8)$ & -1.3 \\
\hline & 1.0 & $120.6 \pm 6.7(8)$ & -2.1 \\
\hline \multicolumn{4}{|l|}{ Exp. 2} \\
\hline \multicolumn{2}{|c|}{ Control (1.0\% CMC Na) } & $113.0 \pm 5.6(6)$ & - \\
\hline \multirow[t]{3}{*}{ DEDC } & 2.0 & $114.7 \pm 7.2(6)$ & -1.5 \\
\hline & 4.0 & $68.7 \pm 8.8(6)^{* *}$ & 39.2 \\
\hline & 6.0 & $45.8 \pm 9.7(6)^{* *}$ & 59.7 \\
\hline \multicolumn{4}{|l|}{ Exp. 3} \\
\hline \multicolumn{2}{|c|}{ Control (1.0\% CMC Na) } & $106.7 \pm 4.9(6)$ & - \\
\hline \multirow[t]{2}{*}{ DS } & 2.0 & $93.2 \pm 7.7(6)$ & 12.6 \\
\hline & 3.0 & $103.0 \pm 9.5(6)$ & 3.5 \\
\hline
\end{tabular}

Mice were decapitated $30 \mathrm{~min}$ after intraperitoneal injection of the drug. Values represent the mean \pm S.E.M. of the results from 6-8 mice. Significantly different from the control $\left({ }^{* *} \mathrm{P}<0.01\right)$.

ic effect induced by DS and DEDC, experiments were carried out at the ambient temperature of $36^{\circ} \mathrm{C}$, which was high enough to maintain body temperature. Under these conditions, the hypothermic effect of DEDC was abolished, but that of DS still remained (Fig. 2, E and F).

As shown in Table 3, at the ambient temperature of $36^{\circ} \mathrm{C}$, both DS and DEDC still exhibited a weak antihypoxic effect. These findings suggest that the anti-hypoxic effect by DS and DEDC could not be explained by the concomitant hypothermia alone.

DEDC is well known to inhibit the copper-zinc form of 

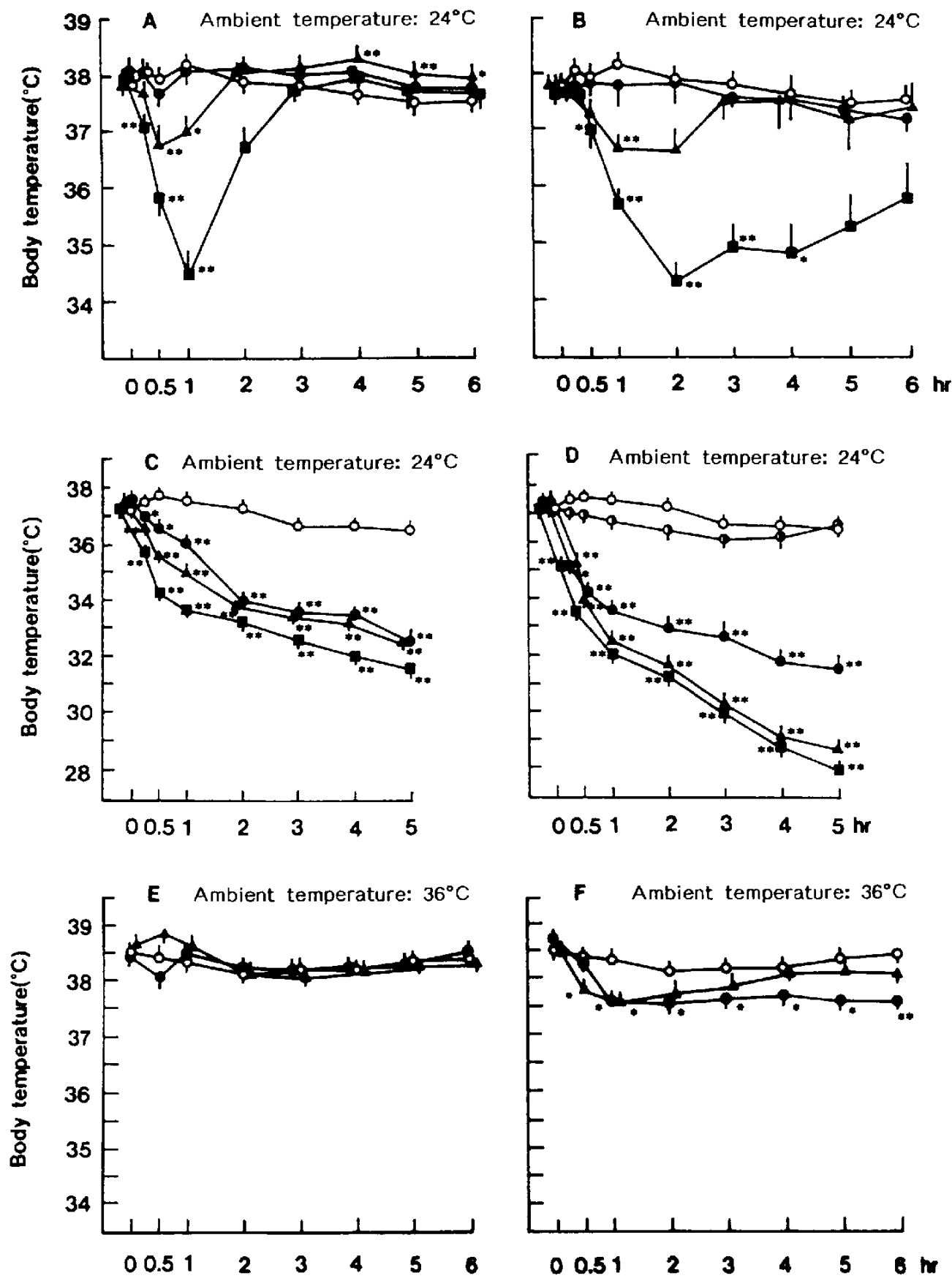

Fig. 2. Time course of changes of the body temperature after intraperitoneal injection of DEDC, DS and DEDC-metal complexes in mice. Control (1.0\% CMC Na) (O); A: DEDC, $0.50(\mathbf{O}) ; 1.00(\mathbf{A}), 2.00(\mathbf{G}) ; \mathbf{B}: \mathrm{DS}, 0.25(\mathbf{O}), 0.50(\mathbf{A}), 1.00(\mathbf{\square}) ; \mathrm{C}$ : $(\mathrm{DEDC})_{2} \mathrm{Cu}, 0.25(\mathrm{O}), 0.50(\boldsymbol{\Lambda}), 1.00(\mathbf{\square}) ; \mathrm{D}:(\mathrm{DEDC})_{2} \mathrm{Zn}, 0.25(\mathrm{O}), 0.50(\mathbf{A}), 1.00(\mathbf{Q}) ;(\mathrm{DEDC})_{3} \mathrm{Fe}, 1.00(\mathrm{O}) ; \mathrm{E}: \mathrm{DEDC}$, $1.00(\mathrm{O}), 2.00(\Delta) ; \mathrm{F}$ : DS, $0.50(\mathrm{O}), 1.00 \mathrm{mmol} / \mathrm{kg}(\mathbf{\Delta})$. Points and bars represent the mean \pm S.E.M. of the results from 7 mice. Significantly different from the control $\left({ }^{*} \mathrm{P}<0.05,{ }^{* *} \mathrm{P}<0.01\right)$.

SOD (5). In the present study, the small doses $(0.50$ to $2.00 \mathrm{mmol} / \mathrm{kg}$ ) of DEDC used did not decrease brain SOD, whereas its high doses markedly decreased the SOD contents. DS did not influence the brain SOD (Table 4). Since the brain SOD level was not changed by the doses of DEDC and DS exhibiting the anti-hypoxic activity, the anti-hypoxic effect may have no definite relationship to the brain SOD contents. However, the possibility that the disappearance of the anti-hypoxic effect with the high dose of DEDC $(6.00 \mathrm{mmol} / \mathrm{kg})$ may be associated with the marked decrease of brain SOD can not be ruled out. 


\section{DISCUSSION}

Both DS and DEDC were found to dose-dependently protect against the lethal effect of hypoxia at the ambient temperature of $24^{\circ} \mathrm{C}$. Especially, the anti-hypoxic effect of DEDC was seen at the smaller doses. The pretreatment time for the maximal effect was less for DEDC than for DS. While maximal effect was observed when DEDC was injected to mice $1 \mathrm{hr}$ before hypoxia, a 3-hr pretreatment prior to hypoxia was needed for the production of the maximal effect with DS. DS is rapidly converted to DEDC and the latter compound subsequently further metabolized to diethylamine, carbon disulfide and DEDC-copper complex, etc. (1-4). The copper complex possessed a remarkable effect, but neither diethylamine nor carbon disulfide did. The zinc complex also exhibited an antihypoxic effect, but the iron complex did not. These findings suggest that DEDC and its copper complex among the metabolites from DS may be involved in the DSinduced anti-hypoxic effect, although the anti-hypoxic effect of DS itself could not be excluded. Conclusive proof will require the demonstration of the relationship between the anti-hypoxic effects of DS and DEDC and their blood contents and/or the influence of a metabolic inhibitor of DS on the anti-hypoxic effect of DS.

Although various copper complexes were reported to possess SOD-like activity (18), the present copper complex $\left(10^{-4} \mathrm{M}\right)$ had no such activity in vitro (data not shown). Higher doses of DEDC that inactivated SOD did not exhibit an anti-hypoxic effect, but remarkable effects were observed at the smaller doses that did not decrease brain SOD content. There have been numerous reports that DS and DEDC possessed an anti-oxidative effect $(9-11,19-22)$. Although there is a great difference between hypoxia- and oxygen-induced tissue injury, the present anti-hypoxic effect was produced in a dose-dependent manner in the low dose range of DEDC, and the disappearance of the anti-hypoxic effect was observed at its higher doses accompanied with the marked decrease in brain SOD level. Such variation of DEDC effects is likely to relate to either an anti-oxidative activity or an indirect pro-oxidative effect via SOD depletion, depending on the dosage used. However, since it remains to be determined if there is a relationship between the anti-oxidative defense mechanisms and acute lethality by hypoxia, it could not be concluded that the anti-oxidative effect with DEDC and DS is involved in prolonging the survival time of mice exposed to hypoxia.

Hypothermia is known to protect animals from hypoxia $(15-17)$. The protective effects of hypothermia against hypoxia are thought to involve decreases in brain metabolic rate and increased affinity of hemoglobin for oxygen $(23,24)$. Namely, under hypoxic conditions, the levels of brain energy reserves and blood oxygen in hypothermic animals were high as compared with those in normothermic animals, resulting in the prolongation of survival time. The hypothermia with DS and DEDC were caused in parallel with the development of the anti-hypoxic effect at the ambient temperature of $24^{\circ} \mathrm{C}$. The time course patterns of the hypothermia with DS and DEDC were in agreement with those of their anti-hypoxic effects, respectively. The hypothermic effect of the complex of DEDC with copper became stronger with time, and there was no recovery from it. Although the time course pattern of the anti-hypoxic effect of the copper complex was not examined, the copper complex may little contribute to the anti-hypoxic effect of DEDC, because the anti-hypoxic effect of DEDC was abolished by $3 \mathrm{hr}$. Furthermore, when the ambient temperature was kept at $36^{\circ} \mathrm{C}$, high enough to maintain body temperature in the mice, DEDC did not cause the decrease in body temperature, but a little of the effect produced by DS still persisted, suggesting that both DS and DEDC abolished the thermoregulation. Under these conditions, both DS and DEDC still exhibited the anti-hypoxic effect. Therefore, these findings indicate that the anti-hypoxic effect of DEDC and DS at the ambient temperature of $24^{\circ} \mathrm{C}$ may be produced not only via the concomitant hypothermia but also by other mechanisms. Further studies are required to clarify the possible mechanisms.

\section{REFERENCES}

1 Eneanya, D.E., Bianchine, J.R., Duran, D.O. and Andresen, B.D.: The actions and metabolic fate of disulfiram. Annu. Rev. Pharmacol. Toxicol. 21, 575-596 (1981)

2 Johansson, B.: Rapid and sensitive on-line precolumn purification and high-performance liquid chromatographic assay for disulfiram and its metabolites. J. Chromatogr. 378, 419-429 (1986)

3 Cobby, J., Meyersohn, M. and Selliah, S.: The rapid reduction of disulfiram in blood and plasma. J. Pharmacol. Exp. Ther. 202, 724-731 (1977)

4 Johansson, B. and Stankiewicz, Z.: Bis-(diethyldithiocarbamate)copper complex: A new metabolite of disulfiram. Biochem. Pharmacol. 43, 2989-2991 (1985)

5 Heikkila, R.E., Cabbat, F.S. and Cohen, G.: In vivo inhibition of superoxide disumutase in mice by diethyldithiocarbamate. $\mathrm{J}$. Biol. Chem. 251, 2182-2185 (1976)

6 Sakaguti, T., Nishimura, H., Masuda, Y., Tsuge, I., Onishi, K. and Tatsumi, H.: The relationship between chemical structure and protective effect of dithiocarbamate derivatives against experimental hepatic injury induced by carbon tetrachloride administration in rats. Biochem. Pharmacol. 15, 756-758 (1966)

7 Strubelt, O., Siegers, C.P. and Schutt, A.: The curative effects of cysteamine, cysteine and dithiocarb in experimental paracetamol poisoning. Arch. Toxicol. 33, 55-64 (1974)

8 Siegers, C.P., Strubelt, O. and Volpel, M.: The antihepatotoxic activity of dithiocarb as compound with six other thio com- 
pounds in mice. Arch. Toxicol. 41, 79-88 (1987)

9 Faiman, M.D., Mehl, R.G. and Oehme, F.W.: Protection with disulfiram from central and pulmonary oxygen toxicity. Biochem. Pharmacol. 20, 3059-3067 (1971)

10 Deneke, S.W. and Fanburg, B.L.: Involvement of glutathione enzymes in $\mathrm{O}_{2}$ tolerance development by diethyldithiocarbamate. Biochem. Pharmacol. 29, $1367-1373$ (1980)

11 Mansour, H., Levacher, M., Gougerot-Pocidalo, M.-A., Rouveix, B. and Pocidalo, J.-J.: Diethyldithiocarbamate provides partial protection against pulmonary and lymphoid oxygen toxicity. J. Pharmacol. Exp. Ther. 236, 476-480 (1986)

12 Deneke, S.M., Bernstein, S.P. and Fanburg, B.L.: Enhancement by disulfiram (antabuse) of toxic effects of 95 to $97 \% \mathrm{O}_{2}$ on the rat lung. J. Pharmacol. Exp. Ther. 208, 377-380 (1979)

13 Forman, H.J., York, J.L. and Fisher, A.B.: Mechanism for the potentiation of oxygen toxicity by disulfiram. J. Pharmacol. Exp. Ther. 212, 452-455 (1980)

14 Heikkila, R.E. and Cobbat, F.: A sensitive assay for superoxide dismutase based on the autoxidation of 6-hydroxy-dopamine. Anal. Biochem. 75, 356-362 (1976)

15 Minard, F.N. and Grant, D.S.: Hypothermia as a mechanism for drug-induced resistance to hypoxia. Biochem. Pharmacol. 31, 1197-1203 (1982)

16 King, G.A.: Protection against hypoxia-induced lethality in mice: a comparison of the effects of hypothermia and drugs. Arch. Int. Pharmacodyn. Ther. 286, 282-298 (1987)
17 Milde, L.N.: The hypoxic mouse model for screening cerebral protective agents: a re-examination. Anesth. Analg. 67, 917922 (1988)

18 Brigelius, R., Spolle, R., Bors, W., Lengfelder, E., Saran, M. and Weser, V.: Superoxide dismutase activity of low molecular weight $\mathrm{Cu}^{2+}$-chelator studies by pulse radiolysis. FEBS Lett. 47, 72-75 (1974)

19 Kuhnlein, U.: Disulfiram inhibits DNA breakage by hydroxy radical-producing agents. Biochim. Biophys. Acta 609, 75-83 (1980)

20 Younes, M. and Siegers, C.-P.: Mechanistic aspects of enhanced lipid peroxidation following glutathione depletion in vivo. Chem. Biol. Interact. 34, 257-266 (1981)

21 Masuda, Y. and Murano, T.: Carbon tetrachloride-induced lipid peroxidation of rat liver microsomes in vitro. Biochem. Pharmacol. 26, 2275-2282 (1977)

22 Koster, J.K. and Van Berkel, T.C.: The effect of diethyldithiocarbamate on the lipid peroxidation of rat liver microsomes and intact hepatocytes. Biochem. Pharmacol. 32, $3307-3310$ (1983)

23 Hagerdal, M., Harp, J., Nilsson, L. and Siesjo, B.K.: The effect of induced hypothermia upon oxygen consumption in the rat brain. J. Neurochem. 24, 311-316 (1975)

24 Carlsson, C., Hagerdal, M. and Siesjo, B.K.: Protective effect of hypothermia in cerebral oxygen deficiency caused by arterial hypoxia. Anesthesiology 44, 27-35 (1976) 